\title{
INFLUÊNCIA DE UMA PRÉ-FORMAÇÃO NO DESENVOLVIMENTO DO ALUNO NO PRIMEIRO ANO DE GRADUAÇÃO
}

Júlia B. A. de Jesus - juliabindi@gmail.com

Centro Federal de Educação Tecnológica de Minas Gerais

R. Professor Benedito Loureiro de Lima, 236, Jardim Esplanada

13202-120 - Jundiaí - São Paulo

Sandro R. Dias - sandrord@cefetmg.br

Departamento de Computação - CEFET-MG

AV. Amazonas, 7675, Nova Gameleira

30510-000 - Belo Horizonte - Minas Gerais

Resumo: A evasão no ensino superior é um fenômeno amplamente estudado. Fatores anteriores ao ingresso na Instituição de Ensino Superior são de grande influência no desenvolvimento do aluno em seu curso superior. Tinto (1975) divide as causas em três áreas: base familiar, experiência escolar e singularidades do indivíduo. O presente estudo, motivado pela experiência pessoal, efetuou o levantamento dos objetivos de campeonatos e olimpíadas realizadas, comumente, durante o ensino médio e uma entrevista sobre a influência do ensino técnico e participação em campeonatos. As competições foram comparadas a fim de levantar as características comuns e analisada a similaridade com as respostas dos questionários. $O$ objetivo do trabalho é averiguar a influência de uma pré-formação, sendo ela uma competição ou ensino técnico, no primeiro ano de graduação. A similaridade entre os fatores demonstrou a relevância da realização de atividades extracurriculares no periodo anterior ao ingresso na Instituição de Ensino Superior.

Palavras-chave: Pré-formação. Influência. Graduação. Evasão. Primeiro ano.

\section{INTRODUÇÃo}

Existe 2.537 Instituições de Educação Superior (IES) no Brasil, que ofertam um total de 13.529.101 vagas gerais, com um total de 3.643.789 remanescentes, segundo o Censo da Educação Superior de 2018. Entretanto, o processo de evasão dos estudantes é uma questão muito questionada e pesquisada. O Instituto Nacional de Estudos e Pesquisas Educacionais Anísio Teixeira (Inep) aponta que dos estudantes que ingressaram no ano de 2010, 58,8\% desistiram da formação superior.

A desilusão com o curso escolhido é resultado da crença superestimada da escolha efetuada. As atividades realizadas não são de completo desconhecimento, todavia, uma vez que a exigência no meio acadêmico é de nível mais elevado do que no ensino médio, a expectativa criada no momento do ingresso na IES é quebrada. Ademais, a realização de socialização no meio acadêmico e social, mostra-se de fundamental importância na correspondência das expectativas. Ambos os meios são necessários, contudo nos casos de ocorrência em um único meio a evasão foi igualmente percebida (CASANOVA E POLYDORO, 2011). 
Biase (2008) separou os fatores de influência sobre a decisão do curso superior desejado em sete categorias distintas. Dentre essas destaca-se a decisão devido ao estudante, em que estão presentes as experiências vivenciadas, aptidão e capacidade física. Entretanto, fatores como mercado de trabalho e família também são relevantes, o que acarreta em uma escolha diferenciada e talvez indesejada, elevando a probabilidade de uma futura evasão. Dessa forma é possível analisar a influência de causas anteriores ao ingresso que resultam na evasão. Tinto (1975) distingue em três áreas diferentes que interferem no processo de saída da IES: base familiar, experiência escolar e singularidades do indivíduo. Dentro dos cursos de Engenharia, os fatores anteriores de maior relevância encontrado são experiências no ensino médio e incentivo familiar (JACKSON, GARDNER E SULLIVAN, 1993).

Motivado pela trajetória pessoal, a presente pesquisa objetiva analisar e relacionar as atividades desenvolvidas no ensino médio em meio competitivo e colaborativo, como meios de descoberta pessoal e influenciadores na decisão de permanência na instituição de ensino superior, através da descoberta individual pelas novas experiências e auxílio na socialização, no meio social e acadêmico, mediante interesse comum entre os indivíduos. Além disso, averiguar a existência de um mesmo resultado, mediante a realização de um ensino técnico como formação prévia ao ingresso no ensino superior.

\section{METODOLOGIA}

Serão determinados as definições dos termos considerados mais abrangente, seguida da apresentação dos objetivos particulares de cada atividades extracurricular selecionada. Posteriormente, será descrito a formulação do questionário responsável pela coleta de informações de experiências prévias ao ensino superior, de acordo com o proposto pela pesquisa. Por fim, é exposta a maneira a qual serão avaliadas as informações disponibilizadas.

\subsection{Definição dos termos}

Foi definido o significado de formação prévia, segundo o Minidicionário Escolar de Língua Portuguesa, como ato de formar um conhecimento de forma anterior ao ingresso no Ensino Superior.

Ademais, é estabelecido como evasão qualquer ato que desvincule o estudante do curso em que inicialmente ingressou na IES

\subsection{Levantamento dos objetivos das atividades extracurriculares}

Os objetivos de todas a competições e olimpíadas selecionadas foram separados segundo o critério de seleção, a experiência pessoal, foram escolhidos todos as atividades extracurriculares em que a participação foi realizada no decorrer do ensino médio. A Tabela 1 contém os torneios que são realizados em equipe, e a tabela 2 refere-se às olimpíadas que trabalham com desenvolvimento individual.

Tabela 1 - Objetivos dos torneios de robótica

\begin{tabular}{|c|c|}
\hline Torneio de robótica & Objetivos \\
\hline \multirow{3}{*}{$\begin{array}{c}\text { Torneio Brasil de Robótica } \\
\text { (TBR) }\end{array}$} & Incentivar a cooperação, integração e participação \\
\cline { 2 - 2 } & Desenvolvimento de disciplina \\
\cline { 2 - 2 } & Promover a iniciativa, empatia e liderança \\
\cline { 2 - 2 } & Manutenção do diálogo \\
\hline
\end{tabular}




\section{Evento On-line}

\begin{tabular}{|c|c|}
\hline & Objetividade na argumentação \\
\hline & Reconhecimento das limitações \\
\hline & Preparo para diferentes torneios científicos e tecnológicos \\
\hline & Contribuir no fortalecimento familiar \\
\hline & Desenvolver trabalho em equipe \\
\hline & Explorar habilidades e ideias novas \\
\hline & Aplicabilidade das ideias \\
\hline First Lego League (FLL) & Satisfação com o desenvolvimento individual e conjunto \\
\hline & Inovação na resolução de problemas \\
\hline & Incentivo a criatividade \\
\hline & Persistência e colaboração \\
\hline & Inserir a ciência moderna nas atividades estudantis \\
\hline & Expansão dos conceitos de robótica escolar \\
\hline & Melhorar a cooperação \\
\hline & Incentivar o pensamento criativo \\
\hline World Robot Olympiad (WRO) & $\begin{array}{l}\text { Desenvolver a habilidade de resolução de problemas por } \\
\text { desafios }\end{array}$ \\
\hline & Melhorar o aprendizado dos alunos \\
\hline & Incentivar a ciência e engenharia \\
\hline & Promover a aplicação da ciência e tecnologia \\
\hline
\end{tabular}

Fonte: Elaborado pelo autor

Tabela 2 - Objetivo das Olimpíadas

\begin{tabular}{|c|c|}
\hline Olimpíada & Objetivos \\
\hline \multirow{5}{*}{ Olimpíada Brasileira de Matemática (OBM) } & $\begin{array}{l}\text { Estimular um aprimoramento dos alunos e } \\
\text { professores }\end{array}$ \\
\hline & Descobrir novos talentos matemáticos \\
\hline & Incentivar a carreira de pesquisa \\
\hline & Apoiar competições regionais no Brasil \\
\hline & $\begin{array}{c}\text { Proporcionar o contato com instituições de } \\
\text { pesquisa }\end{array}$ \\
\hline \multirow{4}{*}{$\begin{array}{c}\text { Olimpíada Brasileira de Matemática de Escolas } \\
\text { Públicas (OBMEP) }\end{array}$} & Incentivar o estudo da matemática \\
\hline & Melhorar a educação brasileira \\
\hline & Disponibilidade de material de qualidade \\
\hline & Incentivo ao ingresso no Ensino superior \\
\hline
\end{tabular}




\begin{tabular}{|c|c|}
\hline & $\begin{array}{l}\text { Promover o desenvolvimento de ciências e } \\
\text { tecnologia }\end{array}$ \\
\hline & Promover a inclusão social \\
\hline \multirow{4}{*}{ Olimpíada de Matemática da Unicamp (OMU) } & Instigar a criatividade \\
\hline & Resolução de problemas desafiadores \\
\hline & Dedicação em atividade árdua \\
\hline & Aprofundamento dos conceitos matemáticos \\
\hline \multirow{3}{*}{ Olimpíada Brasileira de Astronomia (OBA) } & Disponibilizar conhecimentos de astronomia \\
\hline & $\begin{array}{l}\text { Atualizar os alunos e professores acerca do } \\
\text { assunto abordado }\end{array}$ \\
\hline & Incentivar o ensino \\
\hline
\end{tabular}

Fonte: Elaborado pelo autor

\subsection{Elaboração do questionário}

O formulário elaborado de forma digital utilizou o recurso disponibilizado pela Google, pela facilidade de construção e disponibilização. As perguntas contidas foram do tipo múltipla escolha e questão aberta, em que é solicitada a escrita livre. Ademais, o questionário possui duas categorias de perguntas, influência de um ensino técnico e de participação em competições.

A primeira parcela de perguntas é antecedida pelo questionamento de qual foi o ensino médio cursado, técnico ou não. Entretanto, as questões avaliativas da influência exercida é efetuada mediante a realização exclusiva de um ensino técnico. Em caso de realização de um ensino médio padrão, o indivíduo é designado para a pergunta que determina a segunda categoria de questões.

A partir da seleção da opção ensino técnico, o entrevistado é encaminhado para uma série de perguntas. Inicialmente é questionado a especialização do curso técnico e qual curso superior ingressou imediatamente após a conclusão do ensino técnico, a fim de analisar a relação entre o conteúdo estudado dos dois cursos. Ademais, é questionado o auxílio em seu desenvolvimento acadêmico, na socialização e no ingresso em atividades extras. Por fim, é solicitada a escrita, em poucas palavras, sobre a percepção da influência do ensino técnico no curso de graduação, se houve.

Posteriormente, é questionada a participação em competições em olimpíadas durante o período em que cursou o ensino médio, técnico ou não. A partir da resposta é disponibilizado uma nova séries de perguntas acerca da influência da participação nesses eventos.

O novo conjunto de questões, quanto a influência da participação em eventos competitivos, é iniciado pelo questionamento da categorização da competição em questão, se é de cunho coletivo ou individual. A opção ambos também foi disponibilizada, pois há a possibilidade do entrevistado ter participado de diferentes campeonatos, de diferentes categorias.

Além disso, é indagado se é possível relacionar o conteúdo desenvolvido nas competições e no curso superior ingressado imediatamente após a experiência com as competições. Posteriormente, é questionado a influência sobre o desenvolvimento acadêmico e social, assim como a entrada em atividades extras. Por fim, é solicitada a escrita de habilidades adquiridas ou aperfeiçoadas através da experiência em competições, e como, do ponto de vista do entrevistado, influenciou sua experiência acadêmica em geral. 


\subsection{Processo de análise dos dados}

Os objetivos levantados foram analisados de forma a verificar os padrões e formar um modelo padrão para o campeonato, sem alterar a divisão de campeonatos em equipe e individuais. Com o auxílio da fundamentação teórica foram levantados os objetivos que podem acarretar na permanência do estudante no ambiente acadêmico.

Ademais, as sete respostas do questionários foram utilizados em duas partes. As questões referentes às competições foram agrupadas, a fim de traçar um perfil comum e comparada aos objetivos comuns das competições.

A parcela de perguntas quanto a realização de um ensino técnico foi, inicialmente, analisado separadamente e, posteriormente, comparado ao resultado encontrado nas competições, a fim de averiguar um resultado comum entre os dois tipos de experiência prévia ao ensino superior.

\section{RESULTADOS}

A partir da Tabela 1, os objetivos, anteriormente apresentados, foram separados em uma nova tabela de forma que a semelhança dos objetivos se torne perceptível. Dessa forma, foi obtida a Tabela 3, em que podemos observar um perfil padrão dos campeonatos que utilizam do método de trabalho em equipe.

Tabela 3 - Levantamento dos objetivos comuns entre os torneios que utilizam do trabalho em equipe.

\begin{tabular}{|c|c|c|c|}
\hline Objetivos & TBR & FLL & WRO \\
\hline Instigar a criatividade & $\mathrm{x}$ & $\mathrm{x}$ & $\mathrm{x}$ \\
\hline Explorar a resolução de problemas & & $\mathrm{x}$ & $\mathrm{x}$ \\
\hline Exercer cooperação & $\mathrm{x}$ & $\mathrm{x}$ & $\mathrm{x}$ \\
\hline Promover a ciência & $\mathrm{x}$ & $\mathrm{x}$ & $\mathrm{x}$ \\
\hline Preparo científico & $\mathrm{x}$ & & $\mathrm{x}$ \\
\hline Proporcionar a socialização & $\mathrm{x}$ & & \\
\hline Desenvolvimento de disciplina & $\mathrm{x}$ & & \\
\hline Auxílio no vínculo familiar & $\mathrm{x}$ & & \\
\hline Promover a satisfação individual e conjunta & & $\mathrm{x}$ & $\mathrm{x}$ \\
\hline Promover iniciativa e persistência & $\mathrm{x}$ & $\mathrm{x}$ & \\
\hline Expansão dos conceitos de robótica & & & $\mathrm{x}$ \\
\hline
\end{tabular}

Fonte: Elaborado pelo autor

Nota-se o destaque de três objetivos comuns nessa categoria, os quais todos os campeonatos utilizam. Dessa forma, é possível deduzir que são os pontos mais relevantes e característicos de um torneio que exige o uso de uma equipe para participação, sendo esses pontos: promover a criatividade dos participante, exercer cooperação durante o desenvolvimento dos trabalhos, e promover a cultura da ciência. Ou seja, os traços principais dessa categoria de torneios são o desenvolvimento de trabalho em equipe, inovação e propagação da ciência. 
A análise também foi realizada sobre a Tabela 2, em estão presentes os objetivos de competições de cunho individual. A Tabela 4 mostra os objetivos comuns entre as atividades extracurriculares desta categoria.

Tabela 4 - Objetivos comuns das olimpíadas de cunho individual

\begin{tabular}{|c|c|c|c|c|}
\hline Objetivos & OBM & OBMEP & OMU & OBA \\
\hline Estimular o aprimoramento do aluno & $\mathrm{x}$ & $\mathrm{x}$ & $\mathrm{x}$ & $\mathrm{x}$ \\
\hline Descoberta de novos talentos & $\mathrm{x}$ & & & \\
\hline Promover a carreira da pesquisa & $\mathrm{x}$ & $\mathrm{x}$ & & \\
\hline $\begin{array}{c}\text { Gerar contato com Instituições de } \\
\text { pesquisa }\end{array}$ & $\mathrm{x}$ & & & \\
\hline Desenvolvimento da educação do país & & $\mathrm{x}$ & $\mathrm{x}$ & $\mathrm{x}$ \\
\hline $\begin{array}{c}\text { Disponibilidade de um material } \\
\text { diferenciado }\end{array}$ & & $\mathrm{x}$ & & $\mathrm{x}$ \\
\hline Promover a socialização & & $\mathrm{x}$ & & \\
\hline Uso da criatividade & & & $\mathrm{x}$ & \\
\hline Apoiar competições no país & $\mathrm{x}$ & & & \\
\hline Incentivo a realização do ensino superior & & $\mathrm{x}$ & & \\
\hline
\end{tabular}

Fonte: Elaborado pelo autor

Percebe-se que há apenas um objetivo que é comum a todas as olimpíadas analisadas. No entanto existe mais uma característica, a qual foi comum a três das quatro competições, o desenvolvimento da educação do Brasil.

Outrossim, o resultado do questionário apresentou cinco indivíduos que tiveram experiências com competições, dois responderam ter participado de ambos os tipos de competição, dois apenas de cunho colaborativo e um de cunho individual.

Os dois participantes apenas de campeonatos de trabalho em equipe demonstraram um desenvolvimento de trabalho colaborativo e comunicação. $O$ único entrevistado que participou de campeonatos exclusivamente de cunho individual, apresentou um desenvolvimento voltado ao utilizado nas competições que participou e resultou em uma maior facilidade de adaptação e entendimento no conteúdo no curso superior ingressado. Por fim, a participação em ambas as categorias resultou em um que não apresentou influência de sua experiência no ensino superior e o outro apresentou ambos os resultados de influência de competições, âmbito acadêmico e social. Todavia, quatro dos entrevistados demonstraram uma ineficácia na entrada de atividades extras sobre influência de sua participação anterior em competições.

Quanto a realização de um curso técnico, cinco dos seis entrevistados participantes dessa parcela de questões afirmam que os auxiliou no desenvolvimento acadêmico. Além disso, quatro expõem ter tido uma influência sobre o desenvolvimento social, enquanto um não se posiciona e outro nega a relação entre o curso técnico e a socialização no curso superior. Na entrada em atividades extras houve uma divisão de três que acreditam ter auxiliado e outros três que negam essa afirmação.

Por fim, cinco dos participantes afirmam a existência de uma influência positiva entre o ensino técnico a experiência dentro do ensino superior. Ademais, o mesmo número de 


\section{COBENCE

entrevistados mostra auxílio do curso técnico na decisão de qual curso superior ingressou posteriormente.

\section{CONCLUSÃO}

O início do percurso acadêmico, em específico o primeiro ano, possui uma dificuldade maior, em que podem ser percebidos problemas individuais, financeiros e estudantil. $\mathrm{O}$ insucesso pode ter várias origens dentro do cenário individual (FERRAZ e PEREIRA, 2002). Ademais, é o ano de maior probabilidade de evasão, sendo assim, ao ingressar no segundo ano da graduação acarreta em uma diminuição significativa das chances do aluno evadir de seu curso (SILVA FILHO et al, 2007; Silva, 2013; VITELLI E FRITSCH, 2016; Mercuri e Fior, 2017)

A ineficácia, segundo Casanova e Polydoro (2011), em parte, é ocasionada pelo nível inferior elaborado no ensino médio, que gera uma dificuldade de aprender em parte majoritária dos casos. Os autores também enfatizam a necessidade de desenvolvimento nos meios acadêmicos e sociais para um completa integração do indivíduo nas IES. Levanta-se o relacionamento por interesses coletivos como alternativa para realização da socialização como um todo.

Com esse ponto de vista, pode-se verificar que o levantamento do perfil comum das competições analisadas correspondem às necessidades apresentadas para a ocorrência de interação entre os estudantes.

Os torneios em que o trabalho em equipe são obrigatórios, há o desenvolvimento de ciência colaborativa, que visa trazer um novo conhecimento ou ideia ainda não elaborada. Com isso é possível desenvolver uma interação no meio acadêmico, anteriormente mencionado. Ademais, a exigência do trabalho conjunto agrega ao âmbito social individual, a desenvoltura de sociabilização com o próximo, que auxilia no desenrolar da socialização no meio social.

$\mathrm{Na}$ outra categoria de competição, de desenvolvimento individual, o aprimoramento do participante no quesito conhecimento é determinado como prioridade, devido a sua aparição em todos os objetos estudados. Dessa forma corresponde a necessidade de uma melhora na eficiência da educação, que, devido a inferioridade ao nível exigido nas IES, os alunos expressam um desenvolvimento acadêmico dificultoso.

Em comparação com as respostas do questionário aplicado, os objetivos comuns dos campeonatos apareceram como resultado da participação, em sua maioria. Outrossim, conceitos desenvolvidos foram utilizados em estudos posteriores no ensino superior. Entretanto, o incentivo à ciência não foi apresentada como resultado, dessa forma, conclui-se que a participação em atividades extras, como iniciação científica, não é instigada de forma relevante durante a participação em competições desse tipo. Todavia, um ponto que se mostrou muito eficiente na realização de um ensino técnico foi a entrada em atividades extras durante o ensino superior. Assim como as competições, apresentou um desenvolvimento acadêmico e social do indivíduo. Ademais, a influência sobre a decisão do curso superior de ingresso posterior diminui as chances de uma possível evasão, devido a familiaridade com o conteúdo estudado (GUERREIRO-CASANOVA e POLYDORO, 2011).

Portanto, as atividades extracurriculares de cunho competitivo, possuem uma elevada importância no desenvolvimento do estudante que vivencia o primeiro ano do ensino superior. Pois, dentre as características dos campeonatos estão fatores responsáveis por auxiliar no desenvolvimento e melhora em atributos que são apontados como relevantes na tomada de decisão sobre evadir da IES e que demonstraram ser cumpridos no resultado do questionário aplicado. Além disso, o ensino técnico mostra-se muito eficiente no desenvolvimento do aluno, 


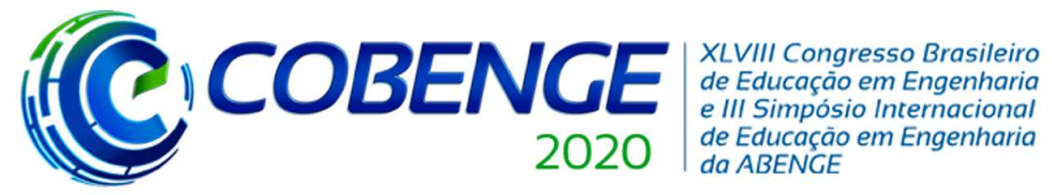

"Os desafios para formar hoje o engenheiro do amanhã"

ponto levantado anteriormente como relevantes na decisão de permanência e uma experiência que influencia na entrada em outras atividades além das obrigatórias, uma vez que o curso superior está relacionado ao conteúdo passado no ensino técnico. Dessa forma, pode-se concluir que a participação em competições e a realização de um ensino técnico são pré-formações que possuem uma influência positiva no ensino superior, de forma a auxiliar no desenvolvimento pessoal e acadêmico. Entretanto, o levantamento efetuado no presente artigo foi majoritariamente teórico. Sendo assim, faz-se necessário a realização de um novo estudo, com a finalidade de um levantamento estatístico da efetividade da influência da participação em campeonatos durante o ensino médio no primeiro ano de graduação, em que o número de entrevistados seja maior.

\section{Agradecimentos}

Agradecemos ao Centro Federal de Educação Tecnológica de Minas Gerais (CEFET-MG) pelo apoio para a participação e apresentação deste trabalho no COBENGE 2020.

\section{REFERÊNCIAS}

BIASE, Érica Giaretta. Motivos de escolha do curso de graduação: uma análise da produção científica nacional. 2008. 130 p. Dissertação (mestrado) - Faculdade de Educação, Universidade Estadual de Campinas, Campinas, 2008.

FERRAZ, M. F.; PEREIRA, A. S. A dinâmica da personalidade e o homesickness (saudades de casa) dos jovens estudantes universitários. Psic., Saúde \& Doenças, Lisboa, v. 3, n. 2, p. 149-164, 2002.

GUERREIRO-CASANOVA, D. C.; POLYDORO, S. A. J. Autoeficácia na formação superior: percepções durante o primeiro ano de graduação. Psicol. cienc. prof., Brasília , v. 31, n. 1, p. 50-65, 2011.

JACKSON, L. A., GARDNER P. D. \& SULLIVAN L. A. Engineering persistence: past, present, and future factors and gender differences. Higher Education, v. 26, p. 227-246, 1993.

MERCURI, E.; ALVES FIOR, C. Análise dos fatores preditivos da evasão em uma Universidade Confessional. Congresos CLABES, 9 out. 2017.

SILVA FILHO, R. L. L. e et al. A evasão no ensino superior brasileiro. Cad. Pesqui., São Paulo, v. 37, n. 132, p. 641-659, Dez. 2007.

SILVA, G. P. Análise de evasão no ensino superior: uma proposta de diagnóstico de seus determinantes. Avaliação (Campinas), Sorocaba, v. 18, n. 2, p. 311-333, Julho 2013.

TINTO, V. Dropout from higher education: a theoretical synthesis of recent research. Review of Educational Research, Washington, v.45, n. 1, p.89-125, 1975.

VITELLI, R. F.; FRITSCH, R. Evasão Escolar na Educação supErior: de que indicador Estamos falando? Estudos em Avaliação Educacional, v. 27, n. 66, p. 908-937, 2016. 


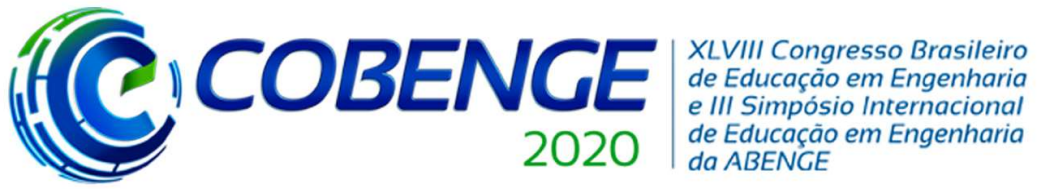

"Os desafios para formar hoje o engenheiro do amanhã"

\section{$\mathrm{O1}$ a $\mathrm{O3}$ de dezembro}

\section{Evento On-line}

\title{
INFLUENCE OF PRE-FORMATION ON STUDENT DEVELOPMENT IN THE FIRST YEAR OF GRADUATION
}

\begin{abstract}
The higher learning evasion is a widely studied phenomenon. Previous factors of the higher learning institution admission are a large influence on the students development in their higher course. Tinto (1975) divided the causes in three sections: family background, scholar experience and individual characteristics. This article, motivated by personal experience, carried out a survey of championships and olympics objectives commonly done during the least years of school and an interview about the influence of technical learning and challenge participation. The competitions were compared in order to get the commons characteristics and analysed the similarity with the quiz answers. The objective of this article is to verify the influence of a pre-formation, competitions or technical education, in the first year of graduation. The similar factors showed the relevance of extracurricular activities realization before the higher learning institution ingress.
\end{abstract}

Keywords: pre-formation, influence, graduation, evasion, first year. 